\title{
Spark Plasma Sintering of Metals and Metal Matrix Nanocomposites: A Review
}

\author{
Nouari Saheb, ${ }^{1,2}$ Zafar Iqbal, ${ }^{1}$ Abdullah Khalil, ${ }^{1}$ Abbas Saeed Hakeem, ${ }^{2}$ Nasser Al Aqeeli, ${ }^{1,2}$ \\ Tahar Laoui, ${ }^{1,2}$ Amro Al-Qutub, ${ }^{1}$ and René Kirchner ${ }^{3}$ \\ ${ }^{1}$ Department of Mechanical Engineering, King Fahd University of Petroleum \& Minerals, Dhahran 31261, Saudi Arabia \\ ${ }^{2}$ Center of Excellence in Nanotechnology, King Fahd University of Petroleum \& Minerals, Dhahran 31261, Saudi Arabia \\ ${ }^{3}$ FCT Systeme GmbH, 96528 Rauenstein, Germany
}

Correspondence should be addressed to Nouari Saheb, nouari@kfupm.edu.sa

Received 23 March 2012; Revised 4 June 2012; Accepted 4 June 2012

Academic Editor: Leonard Deepak Francis

Copyright (C) 2012 Nouari Saheb et al. This is an open access article distributed under the Creative Commons Attribution License, which permits unrestricted use, distribution, and reproduction in any medium, provided the original work is properly cited.

\begin{abstract}
Metal matrix nanocomposites (MMNCs) are those metal matrix composites where the reinforcement is of nanometer dimensions, typically less than $100 \mathrm{~nm}$ in size. Also, it is possible to have both the matrix and reinforcement phases of nanometer dimensions. The improvement in mechanical properties of MMNCs is attributed to the size and strength of the reinforcement as well as to the fine grain size of the matrix. Spark plasma sintering has been used extensively over the past years to consolidate wide range of materials including nanocomposites and was shown to be effective noneconventional sintering method for obtaining fully dense materials with preserved nanostructure features. The objective of this work is to briefly present the spark plasma sintering process and review published work on spark-plasma-sintered metals and metal matrix nanocomposites.
\end{abstract}

\section{Introduction}

Metal matrix composites (MMCs) refer to materials in which rigid ceramic reinforcements are embedded in ductile metal or alloy matrix. MMCs combine metallic properties (ductility and toughness) with ceramic characteristics (high strength and modulus). Attractive physical and mechanical properties such as high specific modulus, strength-to-weigh ratio, fatigue strength, temperature stability, and wear resistance can be obtained with MMCs $[1,2]$. Metal matrix Nanocomposites (MMNCs) are those metal matrix composites where the reinforcement is of nanometer dimensions, typically less than $100 \mathrm{~nm}$ in size [3]. Also, it is possible to have both the matrix and reinforcement phases of nanometer dimensions. Recently, MMNCs received much attraction because of their better properties compared with MMCs. The improvement in mechanical properties is due to the size and strength of the nanosize reinforcement. Also, the fine grain size of the matrix contributes to the improvement of the properties. However, achieving a uniform distribution/dispersion of the nanosize reinforcement phase is not easy using liquid-processing methods because of the difference in densities between the two components of the composite besides the nonwetting between the molten metal and the reinforcement which makes mixing very difficult leading to a heterogeneous structure that affects the properties of the composite. On the other hand, grain growth during sintering of powder metallurgy consolidated products remains a major problem to obtain MMNCs with desired properties [4]. The use of solid-state processing methods such as mechanical alloying [5-8] permitted the development of nanocomposite materials having large volume fraction of nanosize reinforcement phase homogeneously dispersed in a nanostructured matrix. However, the use of conventional sintering methods such as hot pressing, high-temperature extrusion, and hot isostatic pressing to consolidate these materials often results in grain growth which affects the properties of the end product. Preventing or at least minimizing grain growth to maintain the nanostructure features of the matrix is possible through careful control of consolidation parameters, particularly heating rate, sintering temperature, and time. In this regard, spark plasma sintering (SPS), also known as field assisted sintering (FAST), has been shown to be effective noneconventional sintering method for obtaining fully dense 


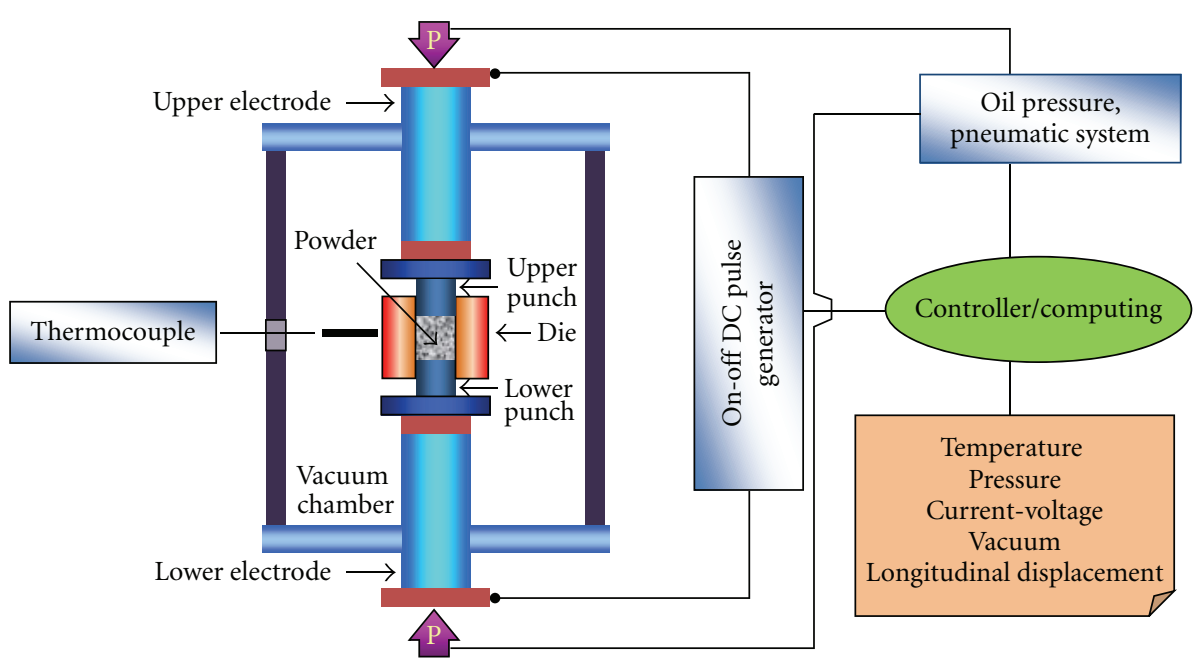

FIGURE 1: Schematic of SPS process.
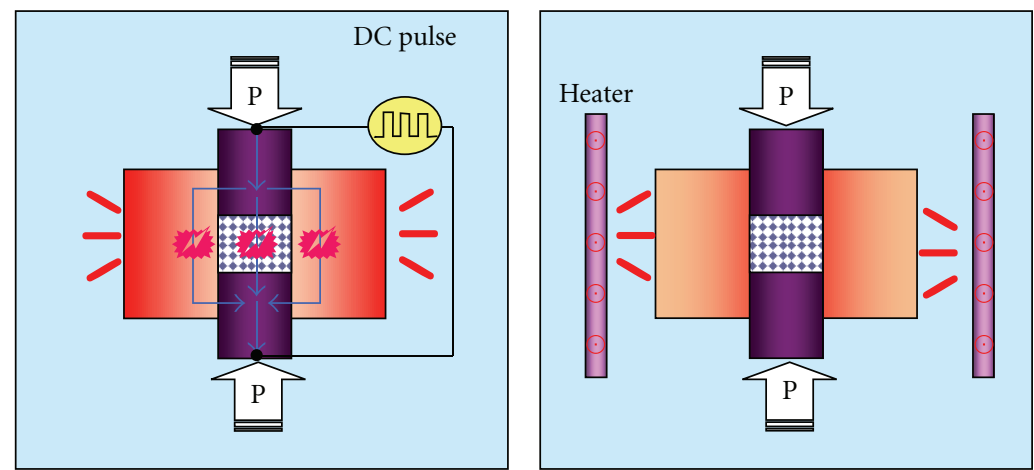

FIGURE 2: Comparison between SPS and conventional sintering.

materials $[9,10]$. The objective of this work is to briefly present the spark plasma sintering process and review published data on spark-plasma-sintered metals and metal matrix nanocomposites.

\section{The Spark Plasma Sintering Process}

Figure 1 shows schematic of the SPS process. The sintering machine is assisted by a uniaxial press, punch electrodes, vacuum chamber, controlled atmosphere, DC pulse generator and position, temperature, and pressure measuring units [11].

Control of sintering temperature is possible through setting the holding time, ramp rate, pulse duration, and pulse current and voltage. The DC pulse discharge could generate spark plasma, spark impact pressure, Joule heating, and an electrical field diffusion effect. In SPS, sintering is assisted by the on-off DC pulse voltage compared to conventional hot pressing as shown in Figure 2. The application of pressure helps plastic flow of the material. Figure 3 illustrates the flow of DC pulse current through the particles.

Usually, SPS is carried out in four main stages as shown in Figure 4. The first stage is performed to remove gases and

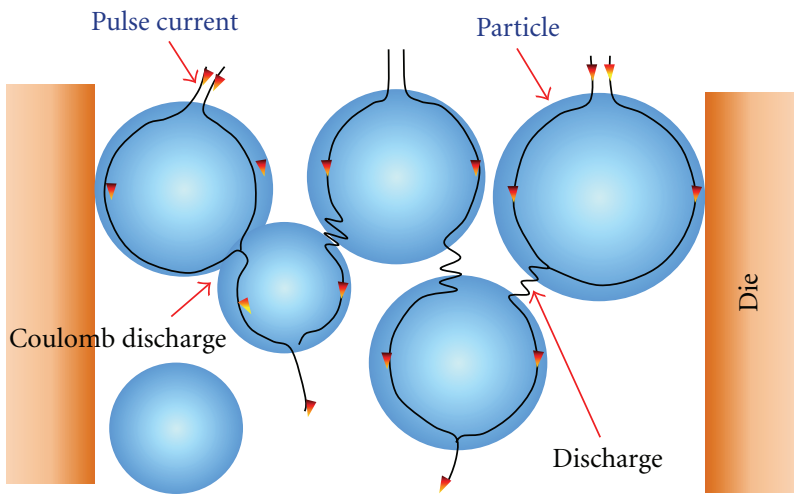

FIGURE 3: DC pulse current flow through the particles.

create vacuum. Then pressure is applied in the second stage followed by resistance heating in the third stage and finally cooling in the fourth stage. When a spark discharge appears in a gap or at the contact point between the particles of a material, a local high-temperature state of several to ten thousands of degrees centigrade is generated momentarily. This causes evaporation and melting on the surface of 


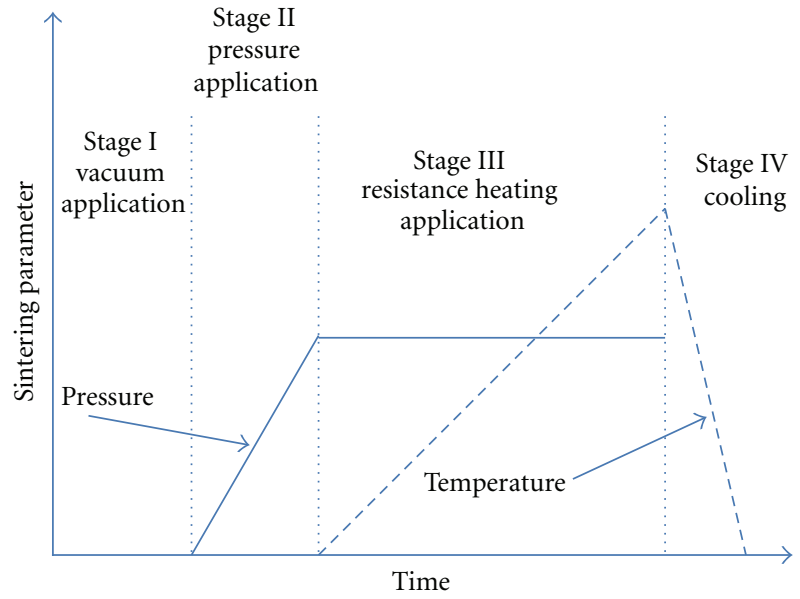

FIGURE 4: Spark plasma sintering stages.

powder particles in the SPS process, and necks are formed around the area of contact between particles. The application of pressure and current, in addition to the high-localized temperatures generated through resistance pulse heating, improves heating rates and reduces sintering time and temperature leading to the consolidation of nanopowders without excessive grain growth. On the other hand, the SPS is not only a binderless process, but also does not require a precompaction step. The powder is directly filled into a graphite die through which current is passed and pressure is applied leading to a fully dense material with superior mechanical properties.

Munir and coworkers [9] have critically examined the important features of SPS method and their individual roles in the observed enhancement of the consolidation process and the properties of the resulting materials. A comprehensive review on the electric current-activated/assisted sintering (ECAS) apparatuses and methods was performed by Grasso and coworkers [10], where the progress of ECAS technology was traced from 1906 to 2008 and 642 ECAS patents published over more than a century were surveyed. An updated and comprehensive description of the development of the electric current-activated/assisted sintering technique for the obtainment of dense materials including nanostructured ones was provided by Orrù et al. [12]. Recently, Hulbert and coworkers [13] opened a discussion on the presence of momentary plasma generated between particles in spark plasma sintering. Using a variety of powders and SPS conditions, they investigated the existence of plasma using in situ atomic emission spectroscopy, direct visual observations, and ultrafast in situ voltage measurements. The authors concluded that there was no plasma, sparking or arcing present during the SPS process, either during the initial or in the final stages of sintering. However, they emphasized the effectiveness of the SPS process to rapidly and efficiently consolidate a wide variety of materials with novel microstructures. More recently, Kieback [14] outlined the fundamentals of spark plasma sintering and critically reviewed past research on the topic. He questioned the importance of alleged electrical effects such as sparks, plasma, heat diffusion, electromigration, or electron wind because of lack of experimental evidence of what really happens inside samples during SPS. He concluded that spark plasma sintering appears not to be fundamentally different from traditional hot pressing, except that the current leads to a much faster heating rate. However, he reiterated the advantages of the very high heating rates, short sintering cycles, and low sintering temperatures that are achieved by SPS. Very recently, some researchers [15] demonstrated that the so-called Branly effect can occur in the early stages of the SPS treatment of preoxidized metallic material due to inductive effects generated by the applied pulsed current and leads to the formation of melting zones between contact areas of copper grains which can enhance material densification.

\section{Spark-Plasma-Sintered Pure Metals}

Diouf and Molinari [16] investigated densification mechanisms in spark plasma sintering using commercial copper powder with three particle size ranges $(<25,25-45$, and $45-$ $90 \mu \mathrm{m})$. They found that under low initial pressure, densification was due to particle rearrangement, localized deformation, bulk deformation, and neck growth. With the increase of pressure, sintering temperature did not significantly influence the sintered density but tensile ductility increased with pressure applied either during or after the bulk densification. In another study, Diouf and coworkers [17] investigated the effect of particle size on the densification mechanism in the temperature range $600-700^{\circ} \mathrm{C}$ and pressure range 20 $30 \mathrm{MPa}$. They found that deformation and neck formation were enhanced by an increase in the particle size. Also, they reported that the extremely high and localized temperature on the contact points between particles leads to melting, giving rise to neck formation. Zhang and coworkers $[18,19]$ showed that high-quality bulk compact can be obtained through spark plasma sintering of fine copper powder in four stages: activation and refining of the powder, formation and growth of the sintering neck, rapid densification, and plastic deformation densification. In another investigation, Zhang and coworkers [20] reported that large-size ultrafine-grained copper with improved mechanical properties having average grain size less than $2.2 \mu \mathrm{m}$ and a relative density greater than $96 \%$ could be prepared by SPS process with initial pressure of $1 \mathrm{MPa}$, holding pressure of $50 \mathrm{MPa}$, sintering temperature of $750^{\circ} \mathrm{C}$, holding time of $6 \mathrm{~min}$, and heating rate of $80^{\circ} \mathrm{C} / \mathrm{min}$. Srivatsan et al. [21] consolidated bulk finegrained copper powder using plasma pressure compaction at two different temperatures under conditions of electrical pulse and noelectrical pulse. They found that pulsing of the powders prior to consolidation led to higher microhardness. They reported increased nanohardness and microhardness with the increase of the temperature of consolidation.

A nanosized copper powder with an average size of $50 \mathrm{~nm}$ was prepared by Zhang and coworkers [22] through a chemical reduction method and consolidated using SPS. In their investigation, they found that the sintering temperature has a significant effect on the relative density and the yield 


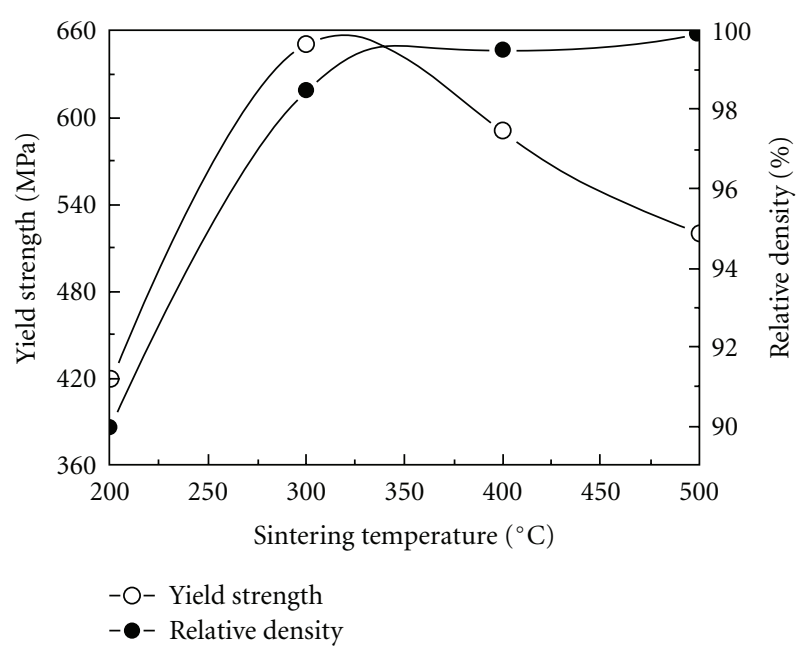

FIGURE 5: Curves of sintering temperature versus relative density and yield strength [22].

strength of the nanocrystalline (NC) bulk copper as it is shown in Figure 5 [22]. They reported that when the sintering temperature is less than $300^{\circ} \mathrm{C}$, the relative density of the NC bulk copper is less than $98.5 \%$. Thus, the relative density is the main factor to decide the yield strength, and the yield strength increases with raising the relative density. When the sintering temperature reaches $350^{\circ} \mathrm{C}$, the relative density of the NC bulk copper exceeds $99 \%$. Hence, the grain size becomes the main factor to decide the yield strength, and the yield strength decreases with increasing the grain size.

Figure 6 [22] shows a typical TEM micrograph of NC bulk copper sintered at a temperature of $300^{\circ} \mathrm{C}$; both nanoscale twins with wide twins spacing of about $60 \mathrm{~nm}$ and narrow twins spacing of less than $2 \mathrm{~nm}$ were present. The authors concluded that NC bulk copper with average grain size of $120 \mathrm{~nm}$, relative density greater than $99 \%$, and yield strength of nearly $650 \mathrm{MPa}$ could be fabricated by SPS with holding pressure of $600 \mathrm{MPa}$, sintering temperature of $350^{\circ} \mathrm{C}$, holding time of $5 \mathrm{~min}$, and heating rate of $100^{\circ} \mathrm{C} / \mathrm{min}$.

The deformation behavior of spark-plasma-sintered $\mathrm{Ni}$ powders with unimodal and bimodal grain size distributions was investigated by Holland et al. [23]. They showed that it is possible to densify nanometric grain size $\mathrm{Ni}$ using fast heating rates and somewhat high uniaxial sintering pressures at low homologous temperatures and retain the low starting grain sizes with little to no grain growth. In another investigation, Holland and coworkers [24] used scanning tunneling microscopy inside the TEM to apply an electric current directly to agglomerated nanometric nickel particles. Figure 7 [24] shows TEM micrographs with SAD patterns for the same agglomerate of four to six particles before and during the annealing experiment. The authors noticed a transformation from the initial soft agglomerate to a stage of early neck formation with relative particle rotation during the first sintering stage which implies mass transfer. Annealing for approximately $145 \mathrm{~s}$ at $10 \mathrm{~V}$ caused rapid consolidation of the particle agglomerate.

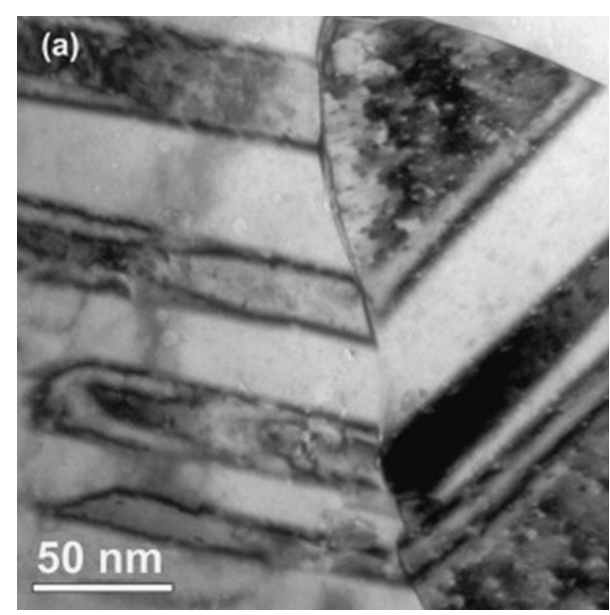

(a)

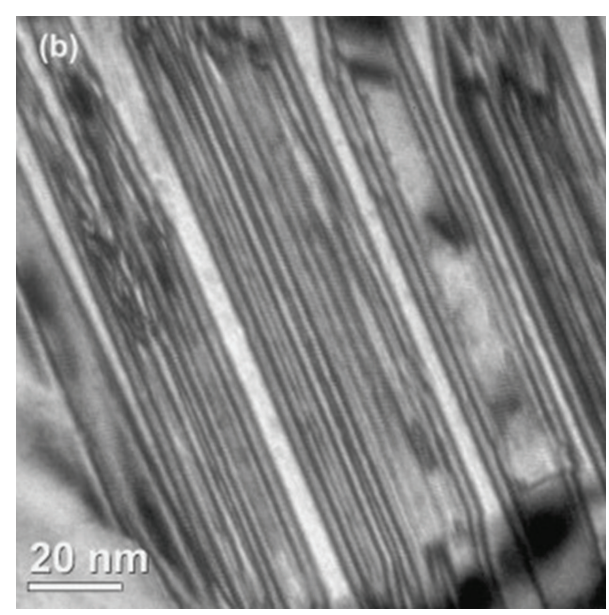

(b)

Figure 6: TEM micrographs of NC bulk copper (a) wide twins spacing and (b) narrow twins spacing [22].

A high-angle annular dark field image of the resulting dense and oval-shaped agglomerate with dimensions ranging between 300 and $600 \mathrm{~nm}$ and some small pores retained in its interior is shown in Figure 8 [24]. Image analysis revealed polycrystallinity with grain boundaries and no apparent interconnected porosity. The authors concluded that consolidation occurs in the absence of an external heat source. Neck formation between adjacent particles and attendant increase in local Joule heating causes rapid densification.

Kodash and coworkers [25] investigated the influence of heating rate $\left(90\right.$ to $1100^{\circ} \mathrm{C} / \mathrm{min}$ ) on densification and final grain structure of spark-plasma-sintered $\mathrm{Ni}$ nanopowders. They found that a moderate heating rate was beneficial for the densification, whereas a high heating rate was conducive to a lower final density. Very high heating rates resulted in nonuniform densification of the samples and formation of cracks during sintering.

The sintering and mechanical behavior of spark-plasmasintered high purity nickel nanopowder was investigated by 


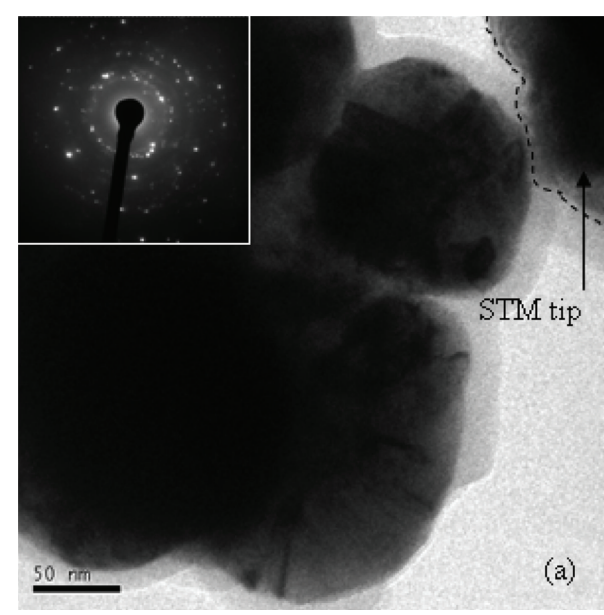

(a)

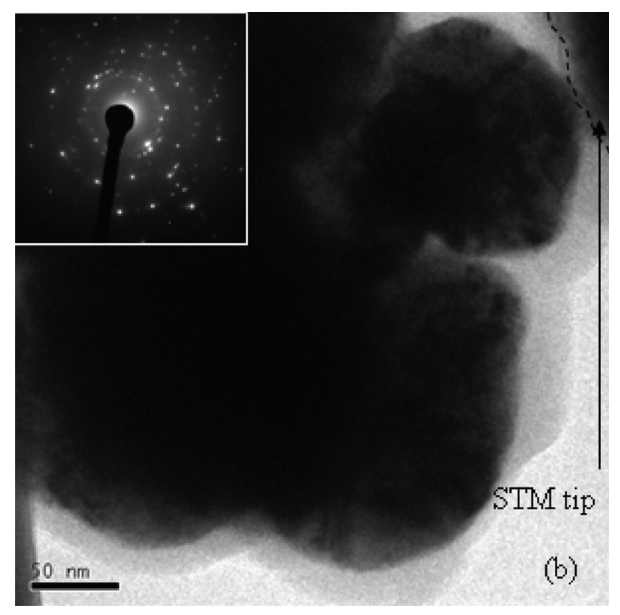

(b)

FIGURE 7: Bright-field images and SAD patterns of Ni agglomerate before (a) and after annealing (b) for $1 \mathrm{~min}$ at $-10 \mathrm{~V}$ [24].

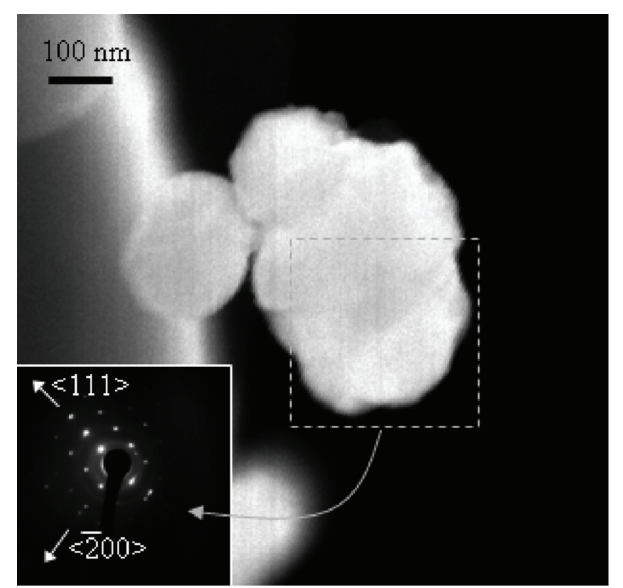

Figure 8: Ex situ high-angle annular dark-field image of the agglomerate after rapid consolidation [24].

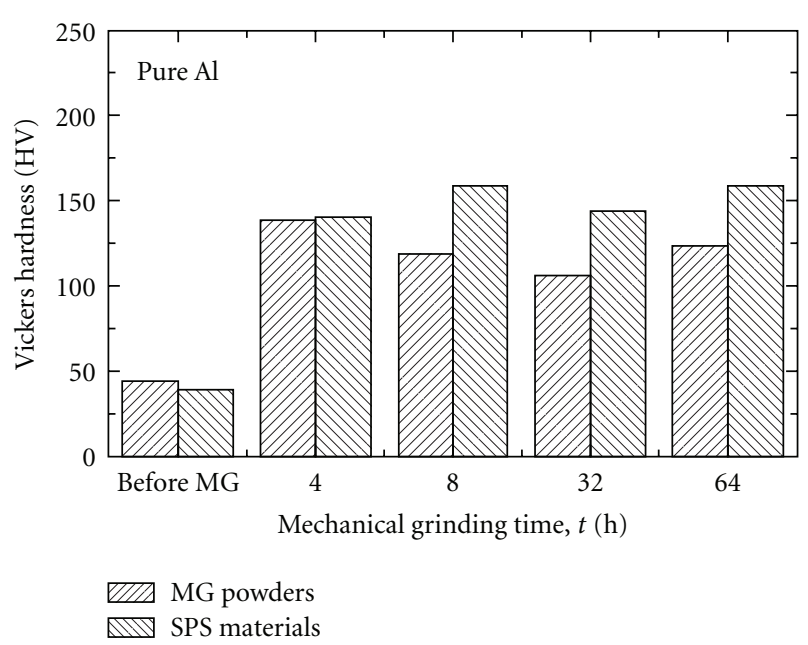

Figure 9: Comparison of hardness between various MG powders and SPS materials [28].

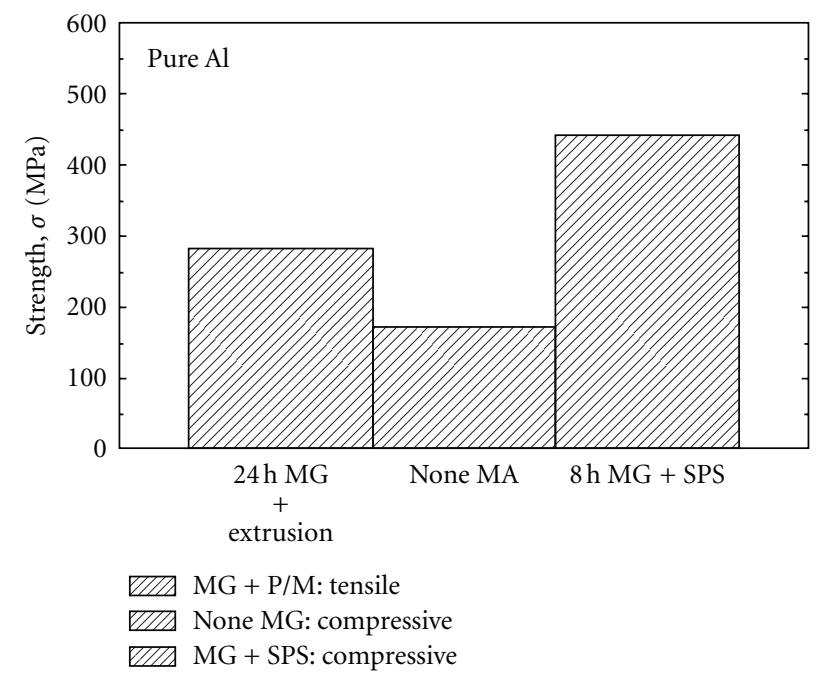

FIGURE 10: Compressive proof strength at room temperature of MG $0 \mathrm{~h}$ and MG $8 \mathrm{~h}$ SPS materials compared with tensile strength of asextruded MG $24 \mathrm{~h}$ P/M [28].

Dirras et al. [26]. Wiedemann et al. [27] studied the effect of sintering parameters on SPS of molybdenum powders and found that specimen sintered at $1400^{\circ} \mathrm{C}$ and $67 \mathrm{MPa}$ exhibited lower hardness as compared to the specimen sintered at same temperature but at $57 \mathrm{MPa}$. However, for much higher temperatures, opposite trend was observed.

Kubota [28] reported great improvement in the hardness and compressive proof stress of mechanically ground pure aluminum sintered by SPS as seen in Figures 9 and 10 [28], respectively. Hardness values of the SPS materials produced from 8,32 , and $64 \mathrm{~h} \mathrm{MG}$ powders were higher than that of the MG powders. Also, compressive proof stress of the $8 \mathrm{~h} \mathrm{MG}$ SPS material ( $440 \mathrm{MPa}$ ) was approximately 2.5 times higher than that of no-MG SPS material (173 MPa). Furthermore, the values were only $20 \%$ lower than that of conventional high-strength 7075-T6 alloy (505 MPa). Also, 
it their characterisations of the solid-state reactions between the MG powder and process control agent (PCA) after heating at temperatures from 573 to $873 \mathrm{~K}$ for $24 \mathrm{~h}$, the authors reported that no solid-state reaction was observed after heating up to $573 \mathrm{~K}$ for $24 \mathrm{~h}$. Formation of $\gamma-\mathrm{Al}_{2} \mathrm{O}_{3}$ occurred in the $4 \mathrm{~h} \mathrm{MG}$ powder after heating at $773 \mathrm{~K}$ for $24 \mathrm{~h}$, whereas the mixture of $\gamma-\mathrm{Al}_{2} \mathrm{O}_{3}$ and $\mathrm{Al}_{4} \mathrm{C}_{3}$ was observed in the $8 \mathrm{~h} \mathrm{MG}$ powder after heating at $773 \mathrm{~K}$ for $24 \mathrm{~h}$. The full density of the SPS material was obtained with the condition of applied pressure at $49 \mathrm{MPa}$ at $873 \mathrm{~K}$ for $1 \mathrm{~h}$.

Spark plasma sintering behavior of pure coarse aluminium powder was reported by Zadra and coworkers [29]. They showed that the presence of the current flow and applying the sintering pressure with a certain delay in respect to the beginning of the cycle promoted better sintering and mechanical properties. With a heating rate of $100 \mathrm{Kmin}$, a sintering temperature of $525^{\circ} \mathrm{C}$, dwell time of $1 \mathrm{~min}$, and pressure of $60 \mathrm{MPa}$, the mechanical properties and the fracture morphology were very similar to those of pure annealed wrought aluminium. Fully dense pure iron with high hardness was obtained through spark plasma sintering Fe nanopowder [30].

\section{Spark Plasma Sintered Alloys}

Skiba et al. [31] studied the effect of varying sintering temperatures and heating rate in spark plasma sintering FeAl intermetallics. They concluded that sintering temperature of $1100^{\circ} \mathrm{C}$ and heating rates up to $400^{\circ} \mathrm{C} / \mathrm{min}$ were the best conditions. Matsugi and coworkers [32] investigated the microstructural properties of SPS titanium aluminide (Ti-53 mol\%Al) at four temperatures that is 1573,1623 , 1648 , and $1673 \mathrm{~K}$ after pulsed electrical discharge and found that the microstructure changed with sintering temperature and the grain growth was prevented. They reported that Vickers microhardness values for each phase in the sintered specimens were almost the same as those in specimens produced by other manufacturing methods. Feng and coworkers [33] investigated the effects of sintering temperature on densification of $\mathrm{TiB} / \mathrm{Ti}-4.0 \mathrm{Fe}-7.3 \mathrm{Mo}$ composites synthesized through mechanical alloying of Ti, Fe65Mo and B powders, and SPS. They obtained a dense composite after sintering at $1000^{\circ} \mathrm{C}$ for $5 \mathrm{~min}$. Specimens with good shape memory effect and density were prepared from $\mathrm{Ti}_{50} \mathrm{Ni}_{50}$ nanopowder through SPS at a temperature of $800^{\circ} \mathrm{C}$ [34]. Below this temperature, specimens had high porosity but with apparent shape memory effect, while specimens sintered at higher temperatures had bulk density and experienced extensive oxidation which led to the loss of the shape memory effect. A high $\mathrm{Nb}$ containing TiAl alloy from prealloyed powder of Ti-45Al-8.5Nb-0.2B-0.2W-0.1Y was processed by SPS [35]. The authors reported that specimens sintered at $1100^{\circ} \mathrm{C}$ were characterized by fine duplex microstructure which led to superior room temperature mechanical properties with a tensile strength of $1024 \mathrm{MPa}$ and an elongation of $1.16 \%$; specimens sintered at $1200^{\circ} \mathrm{C}$ had fully lamellar microstructure with a tensile strength of $964 \mathrm{MPa}$ and an elongation of $0.88 \%$. Couret et al. [36] used SPS technique to densify prealloyed Ti49Al47Cr2Nb2 and Ti51Al44Cr2Nb2B1 powders at temperatures ranging between $1100^{\circ} \mathrm{C}$ and $1250^{\circ} \mathrm{C}$. They achieved full compaction in a short period of time which did not exceed $30 \mathrm{~min}$ and reported promising tensile properties at room temperature and a limited creep resistance at $700^{\circ} \mathrm{C}$. A fine-grained $\mathrm{Ti}-47 \% \mathrm{Al}$ alloy was prepared by double mechanical milling (DMM) and SPS [37]. The main phase $\mathrm{TiAl}$ and $\mathrm{Ti}_{3} \mathrm{Al}$ and $\mathrm{Ti}_{2} \mathrm{Al}$ phases were observed. Samples sintered at $1000^{\circ} \mathrm{C}$ had compressive strength of $2013 \mathrm{MPa}$, compression ratio of $4.6 \%$, and bending strength of $896 \mathrm{MPa}$. Samples sintered at $1100^{\circ} \mathrm{C}$, had compressive strength of $1990 \mathrm{MPa}$, compression ratio of $6.0 \%$, and bending strength of $705 \mathrm{MPa}$. The microhardness of samples sintered at $1000^{\circ} \mathrm{C}$ was higher than that of the samples sintered at $1100^{\circ} \mathrm{C}$.

Amorphous NiTi alloy obtained by mechanical alloying was sintered by SPS [38] and densified samples with $\mathrm{Ni}_{3} \mathrm{Ti}$, $\mathrm{NiTi}$, and $\mathrm{NiTi}_{2}$ phases were produced. Grain sizes were retained to within $500 \mathrm{~nm}$ and $1 \mu \mathrm{m}$ for sintering temperatures of $900^{\circ} \mathrm{C}$ and $1100^{\circ} \mathrm{C}$, respectively. Figure 11 [38] shows TEM images of two compacts [38]. The grains are equiaxed with a size range from 50 to $500 \mathrm{~nm}$ in the sample compacted at $900^{\circ} \mathrm{C}$. From the SAD pattern, the authors found that the grains with stripe-like structure are of the $\mathrm{Ni}_{3} \mathrm{Ti}$ phase, and the one devoid of any internal structure, with grain size around $200 \mathrm{~nm}$ is $\mathrm{NiTi}_{2}$. The phase with grain size less than $100 \mathrm{~nm}$ is NiTi phase according to XRD analysis. For the sample sintered at $1100^{\circ} \mathrm{C}$, areas with the stripe structure also correspond to $\mathrm{Ni}_{3} \mathrm{Ti}$ phase, the phase with round structure which has been observed in SEM is $\mathrm{NiTi}_{2}$ and the grain with dotted-spot is B2-NiTi phase.

$\mathrm{Nb}-\mathrm{Al}, \mathrm{Nb}-\mathrm{Al}-\mathrm{W}, \mathrm{Nb}-\mathrm{Al}-\mathrm{Mo}$, and $\mathrm{Nb}-\mathrm{Al}-\mathrm{N}$ powders prepared by mechanical alloying [39] were sintered by SPS. The authors obtained fully dense $\mathrm{Nb}-\mathrm{Al}$ compacts at sintering temperature higher than $1773 \mathrm{~K}$. However, the microstructure of $\mathrm{Nb}-\mathrm{Al}-\mathrm{W}$ and $\mathrm{Nb}-\mathrm{Al}-\mathrm{Mo}$ compacts was not homogeneous; this was attributed to probably insufficient sintering time. Murakami and coworkers [40] investigated the microstructure, mechanical properties, and oxidation behavior of SPS powder compacts in the $\mathrm{Nb}$ $\mathrm{Si}-\mathrm{B}$ system. They found that the oxidation resistance of $\mathrm{Nb}_{5} \mathrm{Si}_{3} \mathrm{~B}_{2}$ compacts was better than that of $\mathrm{Nb}_{5} \mathrm{Si}_{3}$ compacts, but extremely poorer than that of $\mathrm{NbSi}_{2}$ compacts. Also, they reported that compacts with compositions around the line of $\mathrm{Nb}_{5} \mathrm{Si}_{3}-\mathrm{Nb}_{5} \mathrm{Si}_{3} \mathrm{~B}_{2}-\mathrm{NbB}_{2}$ exhibited high hardness at room temperature and high compressive strength at high temperatures in comparison to those with compositions away from the line. The strength of compacts containing $\mathrm{NbSi}_{2}$ was found to decrease with the increase of the volume fraction of $\mathrm{NbSi}_{2}$ phase. Good quality amorphous alloy billets having very few micropores or crystalline phase particles were obtained through SPS of Cu-based bulk amorphous alloy at a sintering temperature of $480^{\circ} \mathrm{C}$ under a pressure of $80 \mathrm{MPa}$ [41]. A compressive strength of $1.8 \mathrm{GPa}$ was reported which was about $6 \%$ lower than that of the cast amorphous alloy. Shi et al. [42] studied the effect of varying SPS temperature on the properties of $\mathrm{W}-\mathrm{Cu}$ alloy. They found that the specimen sintered at $1200^{\circ} \mathrm{C}$ displayed best mechanical properties. 


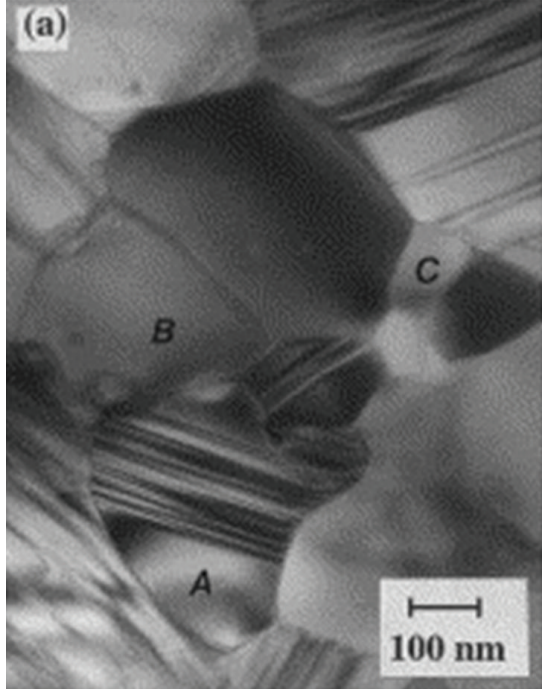

(a)

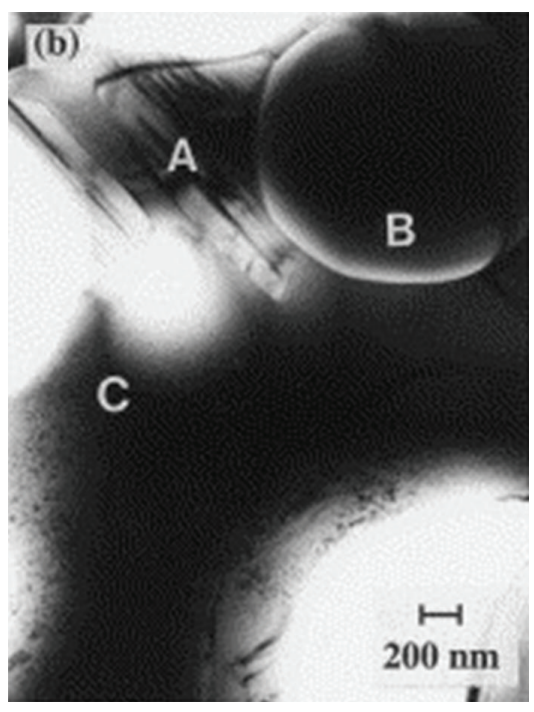

(b)

FIgURE 11: TEM micrographs of as-milled amorphous NiTi powders SPS at (a) $900^{\circ} \mathrm{C} / 50 \mathrm{MPa} / 10 \mathrm{~min}$ and (b) $1100^{\circ} \mathrm{C} / 50 \mathrm{MPa} /$ 10 min. (A) $\mathrm{Ni}_{3} \mathrm{Ti}$; (B) $\mathrm{NiTi}_{2}$; (C) NiTi [38].

Researchers [43] who investigated Al-Mn-Ce system showed that high density, high hardness, and high wear resistance can be achieved in samples processed through SPS. The effect on compressive behavior of spark-plasmasintered Al-5 at.\% Fe alloy has also been studied [44] where substantial increase in compressive strength was reported. Improvement in mechanical properties as a consequence of SPS was also reported by Sasaki and coworkers [45] in AlFe alloy. Bin and coworkers [46] observed the precipitation of two types of $\mathrm{MgZn}_{2}$ particles in spark-plasma-sintered Al$\mathrm{Zn}-\mathrm{Mg}$-Cu alloy. Improvement in mechanical characteristics after spark plasma sintering and after heat treatments was reported in Al-Mg-Si alloy powders [47].

Fully dense Al6061 and Al2124 alloys were obtained through spark plasma sintering [48]. The optimization of process parameters in spark-plasma-sintered Al6061 and $\mathrm{Al} 2124$ alloys [49] showed that $450^{\circ} \mathrm{C}$ is the optimum sintering temperature for achieving full densification and highest hardness. Further increase in temperature had no significant advantage in terms of densification and hardness improvement. Pressure was found to have a negligible effect on the sinterability of specimens. The lowest pressure of $35 \mathrm{MPa}$ at a temperature of $450^{\circ} \mathrm{C}$ produced fully dense and hard specimens. The increase in pressure beyond $35 \mathrm{MPa}$ resulted in grain growth which decreased the hardness.

Akinrinlola and coworkers [50] produced dense bimodal-grained aluminum magnesium alloys by spark plasma sintering of cryomilled powders. They found that the use of a two-stage sintering cycle did not induce grain growth or influence the hardness and flexural strength, but doubled the fracture strength distribution statistic (Weibull modulus) from 13 to 25 . The increased duration of the second hold (from 5 to $20 \mathrm{~min}$ ) marginally increased the Weibull Modulus, from 23 to 25. Cryomilled nanostructured Al 5083 alloy powder was consolidated by SPS [51]. The authors observed both bimodal microstructure and banded structure and attributed them to the starting powder and the process conditions, which are associated with the thermal, electrical, and pressure fields present during SPS. Also, they used a finite element method to investigate distributions in temperature, current, and stress between metallic powder particles.

\section{Spark-Plasma-Sintered Metal Matrix Nanocomposites}

5.1. Al Nanocomposites. Nanocrystalline Al-alloy/SiC nanocomposite powders were synthesized using high-energy ball milling and spark plasma sintering at a temperature of $500^{\circ} \mathrm{C}$ with a heating rate of $300^{\circ} \mathrm{C} / \mathrm{min}$ and a total sintering cycle of $8 \mathrm{~min}$. [52]. A substantial increase of mechanical properties was reported as a result of sintering through SPS. $\mathrm{Al}-20 \mathrm{wt} . \% \mathrm{TiB}_{2}$ nanocomposite was prepared by mechanical alloying of elemental $\mathrm{Ti}, \mathrm{B}$, and $\mathrm{Al}$ powder mixture [5355] and consolidated using spark plasma sintering followed by hot extrusion. The authors used a double-step process to prevent the formation of undesirable phases like $\mathrm{Al}_{3} \mathrm{Ti}$ intermetallic compound. The prepared nanocomposite had good thermal stability against grain growth and particle coarsening. Extruded samples showed a hardness value of $180 \mathrm{VHN}$ and yield and tensile strength of 480 and $540 \mathrm{MPa}$, respectively [54]. A typical stress-strain curve obtained from the extruded sample is shown in Figure 12 [54]. The Al-TiB 2 nanocomposite showed a brittle behavior in tensile testing with a total elongation of $1.4 \%$.

Bulk Al5356- $\mathrm{B}_{4} \mathrm{C}$ nanocomposites with large microhardness and flexural strengths of $244 \mathrm{HV}$ and $707 \mathrm{MPa}$, respectively, were fabricated through cryomilling and spark plasma sintering [56]. Srinivasarao and coworkers [57] developed $\mathrm{Al}-\mathrm{Zr}$ nanocomposite using mechanical alloying and spark plasma sintering. The milled powder was found to consist of either a solid solution of $\mathrm{Zr}$ in $\mathrm{Al}$ or a mixture of $\mathrm{Al}$-solid solution and $\mathrm{Al}_{3} \mathrm{Zr}$ phases. The nanocomposite 


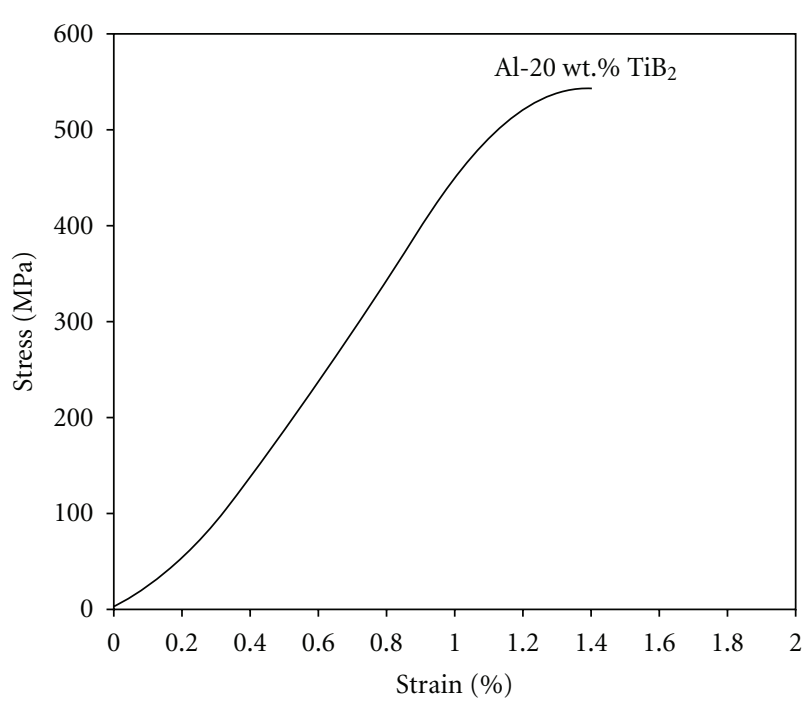

FIGURE 12: A typical stress-strain curve obtained from the extruded $\mathrm{Al}-20 \mathrm{wt} \% \mathrm{TiB}_{2}$ composite [54].

alloys exhibited a high compressive strength of $1 \mathrm{GPa}$ with $10 \%$ plasticity. The authors attributed the high strength to the retention of nanometer-sized grains and also the fine dispersion of the $\mathrm{Al}_{3} \mathrm{Zr}$ phase. The plasticity was explained to be due to excellent bonding between the powder particles and the presence of coarse $\mathrm{Al}$ grains in the matrix. Highly densified carbon nanotube-reinforced aluminum nanocomposites were consolidated through spark plasma sintering and subsequent hot extrusion [58]. The composites had tensile strength three folds higher than pure aluminum. Bhatt and coworkers [59] used high-energy ball milling and spark plasma sintering to produce $\mathrm{Al}-\mathrm{Mg}(0.5,1,2.5$, and 5 by wt.\%) reinforced with 5 wt. $\% \mathrm{SiO}_{2}$ nanocomposites. The authors found that as a result of milling the $\mathrm{Mg}$ was completely dissolved into the $\mathrm{Al}$ matrix, the crystallite size was decreased, and the lattice strain was increased. However, they reported the formation of $\mathrm{MgAl}_{2} \mathrm{O}_{4}$ spinel structure along with $\mathrm{Al}_{2} \mathrm{O}_{3}$ in spark-plasma-sintered samples. The nanocomposites had Vickers hardness twice as high as that of the microcomposites.

Saheb and coworkers [62] successfully produced carbon nanotube-reinforced Al6061 and Al2124 nanocomposites using ball milling and spark plasma sintering. They reported that CNTs were better dispersed, less agglomerated, and had good adhesion to the matrix in composites containing $1 \mathrm{wt} . \%$ CNTs. The increase of CNT content to $2 \mathrm{wt} . \%$ led to the formation of CNT clusters which resulted in less uniform and homogenous composite powders. Almost full densification of Al6061 reinforced with CNTs was achieved at $500^{\circ} \mathrm{C}$. Also, CNTs reinforced $\mathrm{Al} 2124$ nanocomposites reached very high densities at $500^{\circ} \mathrm{C}$. Composites reinforced with $1 \mathrm{wt} . \%$ CNTs displayed better densification compared to composites containing $2 \mathrm{wt} . \% \mathrm{CNTs}$. The increase of CNTs content from 0.5 to $1 \mathrm{wt} . \%$ increased the hardness of the Al6061 and Al2124 alloys to maximum values. Further increase of CNTs content to 2 wt.\% decreased the hardness to values lower than that of the monolithic alloys. In another investigation, Al-Qutub and coworkers [63] investigated the friction and wear behavior of Al6061 monolithic alloy and 1 wt.\% CNTs reinforced Al6061 nanocomposite prepared through ball milling and spark plasma sintering. They found that, under mild wear conditions, the composite displayed lower wear rate and friction coefficient compared to the monolithic alloy. However, for severe wear conditions, the composite displayed higher wear rate and friction coefficient compared to the monolithic alloy. Also, they clarified that the friction and wear behavior of Al-CNT composites is largely influenced by the applied load and there exists a critical load beyond which CNTs could have a negative impact on the wear resistance of aluminum alloy.

5.2. Cu Nanocomposites. Dash and coworkers [60] reinforced copper matrix with 5,10 , and 15 vol.\% alumina particles (average size $5.71 \mu \mathrm{m}$ ) to prepare microcomposites and conventionally sintered them under $\mathrm{N}_{2}, \mathrm{H}_{2}$, and Ar atmospheres. Also, they reinforced the same matrix with 1, 5, 7 vol.\% alumina (average size $<50 \mathrm{~nm}$ ) to prepare nanocomposites and consolidated them through spark plasma sintering. The authors reported maximum Vickers hardness of 60,75 , and 80 for $\mathrm{Cu}-15$ vol. $\% \mathrm{Al}_{2} \mathrm{O}_{3}$ conventionally sintered in $\mathrm{N}_{2}, \mathrm{Ar}$, and $\mathrm{H}_{2}$ atmosphere, respectively, and maximum hardness value of 125 for the $\mathrm{Cu}-5$ vol. $\% \quad \mathrm{Al}_{2} \mathrm{O}_{3}$ nanocomposite prepared by spark plasma sintering. Also, they observed that $\mathrm{Cu}-\mathrm{Al}_{2} \mathrm{O}_{3}$ composite showed poor mechanical properties when it was conventionally sintered in $\mathrm{N}_{2}$ or $\mathrm{Ar}$ atmosphere compared to $\mathrm{H}_{2}$ atmosphere. Hardness for $\mathrm{Cu}-\mathrm{Al}_{2} \mathrm{O}_{3}$ microcomposites and nanocomposites fabricated using conventional and spark plasma sintering is shown in Figures 13(a) and 13(b), respectively [60]. Microcomposites sintered in hydrogen showed higher hardness than those sintered in nitrogen. The latter had hardness close to that of microcomposites sintered in argon. The hardness of the nanocomposites showed an increase up to 5 vol.\% alumina and then a decrease of the hardness for 7 vol. $\%$ alumina. The authors believed that 7 vol.\% alumina may facilitate higher degree of agglomeration of alumina nanoparticles but till 5 vol. \% alumina the agglomeration seems to be insignificant. Also, 5 vol.\% of alumina may resulted in effective dispersion strengthening associated with small-scale pinning in the nanocomposite, which prevents grain growth leading to higher hardness.

Copper and nanodiamond with 20 at.\% C powders were mechanically alloyed and consolidated via hot extrusion or spark plasma sintering to produce $\mathrm{Cu}$-diamond nanocomposites [64]. A novel fabrication technique consisting of molecular level mixing and controlled oxidation process was proposed by $\mathrm{Lim}$ et al. [65] for the production of $\mathrm{CNT} / \mathrm{Cu}$ nanocomposite powders. The fabricated $\mathrm{CNT} / \mathrm{Cu}_{2} \mathrm{O}$ nanocomposites were reduced to $\mathrm{CNT} / \mathrm{Cu}$ nanocomposite powders with $\mathrm{H}_{2}$ gas and then consolidated through SPS. The authors reported that hot compression enhanced the ductility, strength, and electrical conductivity of the $\mathrm{CNT} / \mathrm{Cu}$ nanocomposites. In situ synthesis of $\mathrm{TiB}_{2}-\mathrm{Cu}$ composites [66] starting from powder mixtures 


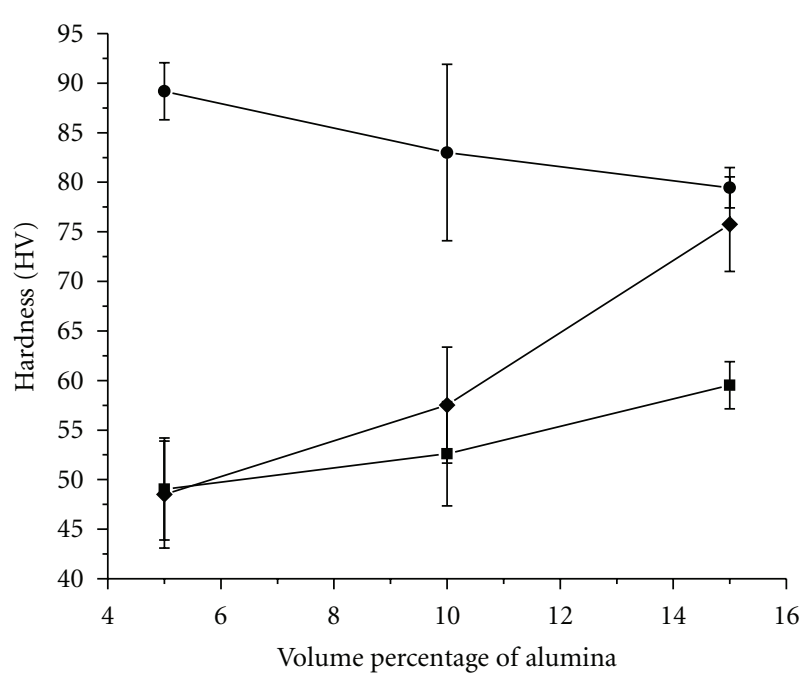

(a)

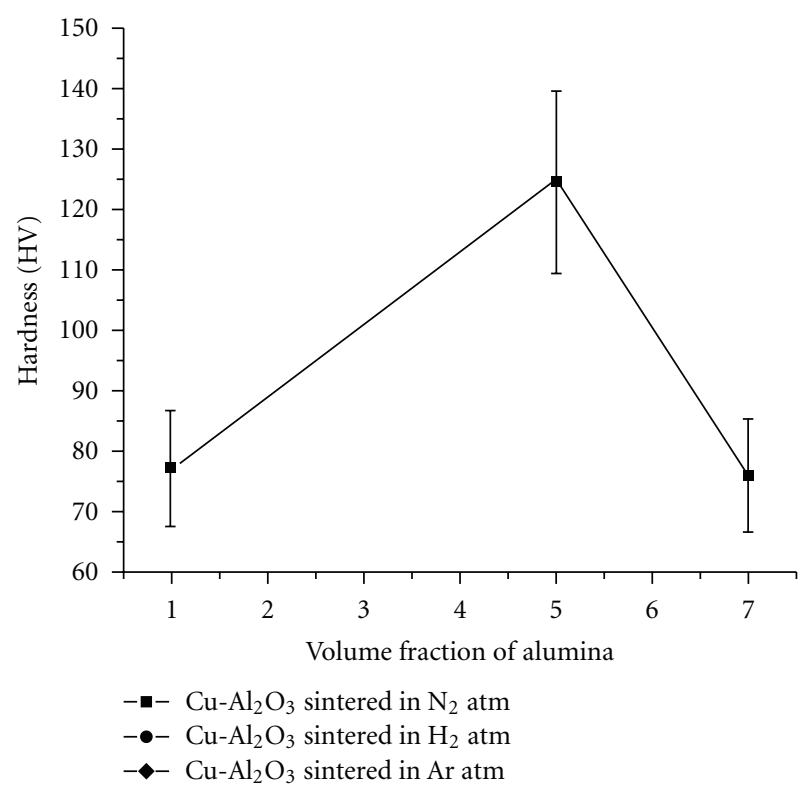

(b)

FIGURE 13: Comparison of hardness for $\mathrm{Cu}-\mathrm{Al}_{2} \mathrm{O}_{3}$ microcomposites (a) and $\mathrm{Cu}-\mathrm{Al}_{2} \mathrm{O}_{3}$ nanocomposites (b) fabricated using conventional and spark plasma sintering, respectively [60].

with full conversion into $\mathrm{TiB}_{2}$ phase was reported. The authors used SPS to obtain a highly conductive 4.5 vol. $\%$ $\mathrm{TiB}_{2}-\mathrm{Cu}$ nanocomposite with $82-87 \%$ IACS (International Annealed Copper Standard) conductivity. Synthesis of $\mathrm{TiB}_{2}-$ $\mathrm{Cu}$ nanocomposites was reported in other studies [67-70]. Authors reported that the increase of $\mathrm{TiB}_{2}$ content from 2.5 up to 7.5 wt. \% resulted in a 1.5 -fold increase in yield strength, tensile strength, and hardness and 5-fold increase in wear resistance with only $10 \%$ decrease in conductivity [67]. Also, SPS at $650^{\circ} \mathrm{C}$ for $30 \mathrm{~min}$ under $50 \mathrm{MPa}$ was reported to decrease the electrical conductivity from 75 to $54 \%$ IACS with increasing $\mathrm{TiB}_{2}$ content from 2.5 to $10 \mathrm{wt} . \%$. Hardness increased from 56 to $97 \mathrm{H}_{\mathrm{R}} \mathrm{B}$ and tensile strength increased with increasing $\mathrm{TiB}_{2}$ content [68]. Hanada and coworkers synthesized homogeneous $\mathrm{Cu}$ nanocomposites containing 0 30 at \% diamond nanoparticles through mechanical milling and spark plasma sintering followed by hot extrusion [71]. Kim et al. [72] prepared $\mathrm{Cu}$ matrix nanocomposites by spark plasma sintering, high-energy ball-milled nanosized $\mathrm{Cu}$ powders, and MWCNTs followed by cold rolling. The $\mathrm{CNT} / \mathrm{Cu}$ nanocomposites showed a tensile strength of $281 \mathrm{MPa}$, which is approximately 1.6 times higher than that of monolithic $\mathrm{Cu}$. In another study [73], carbon-nanotube(CNT-) reinforced $\mathrm{Cu}$ matrix $(\mathrm{CNT} / \mathrm{Cu})$ nanocomposites were fabricated by a novel fabrication process, named as molecular level process, which involves suspending CNTs in solvent by surface functionalization, mixing $\mathrm{Cu}$ ions with CNT suspension, drying, calcination, and reduction. The nanocomposites were consolidated by SPS. The authors reported the enhancement of hardness and sliding wear resistance by two and three times, respectively, of the SPS consolidated nanocomposite compared to those of $\mathrm{Cu}$ matrix.

5.3. Fe Nanocomposites. $\mathrm{Fe}-\mathrm{Al}_{2} \mathrm{O}_{3}$ nanocomposite was synthesized by reactive milling of $\mathrm{Fe}-\mathrm{Al}_{2} \mathrm{O}_{3}-\mathrm{Al}-\mathrm{Fe}$ powder mixture in toluene medium and consolidated by SPS. The nanocomposite showed heterogeneous grain structure of Fe consisting of nano-, submicron-, and micron-size grains together with nanometer $\mathrm{Fe}-\mathrm{Al}_{2} \mathrm{O}_{3}$ particles. The nanocomposites consolidated at $800^{\circ} \mathrm{C}$ had a hardness of $795 \mathrm{MPa}$ [74]. Fe/Cr- $\mathrm{Al}_{2} \mathrm{O}_{3}$ nanocomposite powders were prepared by $\mathrm{H}_{2}$ selective reduction of oxide solid solutions and consolidated by SPS [75]. The composites showed a lower microhardness and higher fracture strength than unreinforced alumina. The friction coefficient against an alumina ball was lower, because of the presence of the intergranular metal particles; however, $\mathrm{FeAl}_{2} \mathrm{O}_{4}$ grains formed during SPS were beneficial for higher cycle numbers. Li and coworkers [76] synthesized nanocomposite $\mathrm{Nd}_{2} \mathrm{Fe}_{14} \mathrm{~B} / \alpha$-Fe magnets using Fe nanoparticles prepared by sonochemical treatment of carbonyl iron which were applied to coat micrometersized $\mathrm{Nd}_{2} \mathrm{Fe}_{14} \mathrm{~B}$ permanent magnetic powder. The bulk nanocomposite was consolidated using SPS. The authors obtained magnets with $B_{r}$ of $0.86 \mathrm{~T}, H_{\mathrm{ci}}$ of $683.8 \mathrm{kA} / \mathrm{m}$ and $(\mathrm{BH})_{\max }$ of $95.92 \mathrm{~kJ} / \mathrm{m}^{3}$. They also reported that a high ballmilling pretreatment was helpful for obtaining magnets with fine grains and even microstructure with an increase of the $B_{r}$ and $(\mathrm{BH})_{\max }$ to $0.94 \mathrm{~T}$ and $113.6 \mathrm{~kJ} / \mathrm{m}^{3}$, respectively.

Libardi and coworkers [61] produced iron-based nanocomposite reinforced with nanometric silica and used thermal analysis to calculate the activation energy of the grain growth process and extrapolate the temperature at which the powder could be consolidated by SPS without losing nanostructure. They found that without the addition of $\mathrm{SiO}_{2}$, the hardness was constant up to $400^{\circ} \mathrm{C}$, whereas the dispersion of $\mathrm{SiO}_{2}$ kept a constant hardness value up to $600^{\circ} \mathrm{C}$. Also, the powders lost the nanostructure after annealing at $600^{\circ} \mathrm{C}$ for the material without $\mathrm{SiO}_{2}$ and above $750^{\circ} \mathrm{C}$ with $\mathrm{SiO}_{2}$ addition. Microhardness results as a function of annealing temperature are presented in Figure 14 


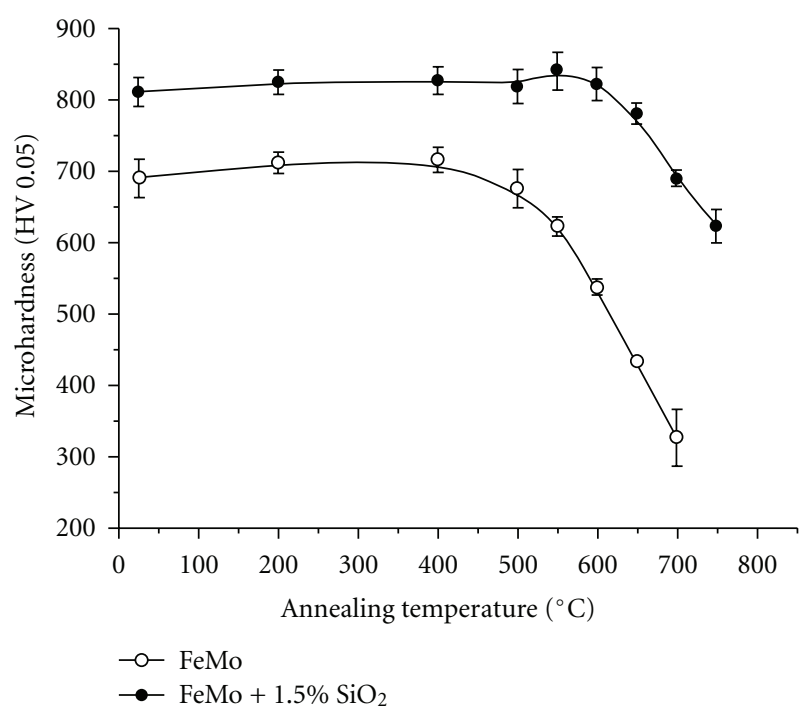

FIGURE 14: Microhardness as a function of annealing temperature [61].

[61]. The "FeMo $+\mathrm{SiO}_{2} 20 \mathrm{~h}$ " nanocomposite had a thermal stability remarkably higher than the "FeMo $20 \mathrm{~h}$ " nanocomposite. Without addition of silica, the powder kept constant the initial hardness up to $400^{\circ} \mathrm{C}$, but above $500^{\circ} \mathrm{C}$ it softened. With the addition of silica nanoparticles, the material was not affected by thermal treatments up to $600^{\circ} \mathrm{C}$ and softened only above $650^{\circ} \mathrm{C}$, and even after annealing at $750^{\circ} \mathrm{C}$ for $1 \mathrm{~h}$, it remained considerably hard.

Highly dense iron-based amorphous alloy and its tungsten particulate-reinforced composites were consolidated by SPS [77]. The authors reported the partial devitrification of amorphous matrix into nanocrystalline $\mathrm{Fe}_{23}(\mathrm{C}, \mathrm{B})_{6}$ during sintering which led to the formation of in situ amorphous matrix composites. Also, they successfully fabricated ex situ amorphous matrix composites reinforced with micron-size tungsten particles.

5.4. Other Nanocomposites. Udhayabanu and coworkers [78] developed $\mathrm{Ni}-30$ vol. $\% \mathrm{Al}_{2} \mathrm{O}_{3}$ in situ nanocomposite through reaction milling of $\mathrm{NiO}-\mathrm{Al}-\mathrm{Ni}$ powder mixture followed by SPS. The nanocomposite had hardness and yield strength approximately two times higher than that of pure $\mathrm{Ni}$ of similar grain size. A nickel-matrix composite with MWNT [79] was prepared by slurry mixing process using ethanol as a solvent. The SPS-sintered relative densities of the composites containing up to $5 \mathrm{vol} \%$ of MWNT were above $99 \%$. The thermal conductivity was found to increase by $10 \%$ for the composition with 3 vol\% MWNT. $\mathrm{Al}_{2} \mathrm{O}_{3} / \mathrm{Ni}$ nanocomposite was also prepared through pulse electric current sintering [80]. Umeda and coworkers [81] prepared magnesium reinforced with CNTs and $\mathrm{Mg}_{2} \mathrm{Si} / \mathrm{MgO}$ compounds. They used amorphous and porous silica particles originated from rice husks, which were coated with CNTs and contained nanotubes in the pores. The in situ synthesis of $\mathrm{Mg}_{2} \mathrm{Si}$ and $\mathrm{MgO}$ via deoxidization and oxidation reaction occurred from the elemental mixture of pure magnesium and $\mathrm{CNT}-\mathrm{SiO}_{2}$ composite particles through SPS. They reported a low and stable friction coefficient and a decreased wear rate with increased CNTs and $\mathrm{Mg}_{2}$ Si content.

\section{Conclusion}

In this work, the spark plasma sintering process was presented and recently published work on spark-plasmasintered metals and metal matrix nanocomposites was reviewed. The spark plasma sintering process has been shown to be an effective technique for consolidating metallic materials including nanocomposites. The advantages of spark plasma sintering such as high heating rates, short sintering cycles, and low sintering temperatures that allow sintering nanostructured materials were emphasized by all researchers. However, more experimental work is needed to better understand the SPS process and prove the existence or absence of some phenomenon such as plasma, sparks, electromigration, and Branly effect.

\section{Acknowledgment}

The authors would like to acknowledge the financial support from King Abdul Aziz City for Science and Technology (KACST) through Project no. ARP-28-122.

\section{References}

[1] L. Ceschini, G. Minak, and A. Morri, "Tensile and fatigue properties of the AA6061/20 vol\% $\mathrm{Al}_{2} \mathrm{O}_{3 p}$ and AA7005/10 vol\% $\mathrm{Al}_{2} \mathrm{O}_{3 p}$ composites," Composites Science and Technology, vol. 66, no. 2, pp. 333-342, 2006.

[2] I. J. Shon and H. S. Kang, "Properties and fast low-temperature consolidation of nanocrystalline $\mathrm{Ni}-\mathrm{ZrO}_{2}$ composites by highfrequency induction heated sintering," Journal of Alloys and Compounds, vol. 509, pp. 2964-2969, 2011.

[3] C. Suryanarayana, "Synthesis of nanocomposites by mechanical alloying," Journal of Alloys and Compounds, vol. 509, supplement 1, pp. S229-S234, 2011.

[4] V. Viswanathan, T. Laha, K. Balani, A. Agarwal, and S. Seal, "Challenges and advances in nanocomposite processing techniques," Materials Science and Engineering R, vol. 54, no. 5-6, pp. 121-285, 2006.

[5] C. Suryanarayana, "Mechanical alloying and milling," Progress in Materials Science, vol. 46, no. 1-2, pp. 1-184, 2001.

[6] S. Kamrani, R. Riedel, S. M. S. Reihani, and H. J. Kleebe, "Effect of reinforcement volume fraction on the mechanical properties of $\mathrm{Al}-\mathrm{SiC}$ nanocomposites produced by mechanical alloying and consolidation," Journal of Composite Materials, vol. 44, no. 3, pp. 313-326, 2010.

[7] S. H. Hwang, D. S. Bang, K. H. Yoon, Y. B. Park, D. Y. Lee, and S. S. Jeong, "Fabrication and characterization of aluminumcarbon nanotube powder and polycarbonate/aluminumcarbon nanotube composites," Journal of Composite Materials, vol. 44, no. 23, pp. 2711-2722, 2010.

[8] M. K. Habibi, K. S. Tun, and M. Gupta, "An investigation into the effect of ball milling of reinforcement on the enhanced mechanical response of magnesium," Journal of Composite Materials, vol. 45, no. 24, pp. 2483-2493, 2011.

[9] Z. A. Munir, U. A. Tamburini, and M. Ohyanagi, "The effect of electric field and pressure on the synthesis and consolidation 
of materials: a review of the spark plasma sintering method," Journal of Materials Science, vol. 41, no. 3, pp. 763-777, 2006.

[10] S. Grasso, Y. Sakka, and G. Maizza, "Electric current activated/assisted sintering (ECAS): a review of patents 19062008," Science and Technology of Advanced Materials, vol. 10, no. 5, Article ID 053001, 2009.

[11] H. U. Kessel, J. Hennicke, R. Kirchner, and T. Kessel, "Rapid sintering of novel materials by FAST/SPS - further development to the point of an industrial production process with high cost efficiency," FCT Systeme GmbH, Rauenstein, Germany, 2010.

[12] R. Orrù, R. Licheri, A. M. Locci, A. Cincotti, and G. Cao, "Consolidation/synthesis of materials by electric current activated/assisted sintering," Materials Science and Engineering $R$, vol. 63, no. 4-6, pp. 127-287, 2009.

[13] D. M. Hulbert, A. Anders, J. Andersson, E. J. Lavernia, and A. K. Mukherjee, "A discussion on the absence of plasma in spark plasma sintering," Scripta Materialia, vol. 60, no. 10, pp. 835838, 2009.

[14] B. Kieback, "A review of spark plasma sintering," in Proceedings of the Hagen Symposium, Hagen, Germany, November 2011.

[15] P. Guyot, V. Rat, J. F. Coudert, F. Jay, A. Maître, and N. Pradeilles, "Does the Branly effect occur in spark plasma sintering?" Journal of Physics D, vol. 45, no. 9, Article ID 092001, 2012.

[16] S. Diouf and A. Molinari, "Densification mechanisms in spark plasma sintering: effect of particle size and pressure," Powder Technology, vol. 221, pp. 220-227, 2012.

[17] S. Diouf, C. Menapace, and A. Molinari, "Study of effect of particle size on densification ofcopper during spark plasma sintering," Powder Metallurgy. In press.

[18] Z. Zhaohui, W. Fuchi, W. Lin, L. Shukui, and S. Osamu, "Sintering mechanism of large-scale ultrafine-grained copper prepared by SPS method," Materials Letters, vol. 62, no. 24, pp. 3987-3990, 2008.

[19] Z. H. Zhang, F. C. Wang, L. Wang, S. K. Li, M. W. Shen, and S. Osamu, "Microstructural characteristics of large-scale ultrafine-grained copper," Materials Characterization, vol. 59, no. 3, pp. 329-333, 2008.

[20] Z. H. Zhang, F. C. Wang, L. Wang, and S. K. Li, "Ultrafinegrained copper prepared by spark plasma sintering process," Materials Science and Engineering A, vol. 476, no. 1-2, pp. 201205, 2008

[21] T. S. Srivatsan, B. G. Ravi, A. S. Naruka, L. Riester, S. Yoo, and T. S. Sudarshan, "Microstructure and hardness of copper powders consolidated by plasma pressure compaction," Journal of Materials Engineering and Performance, vol. 10, no. 4, pp. 449455, 2001.

[22] Z. H. Zhang, F. C. Wang, S. K. Lee, Y. Liu, J. W. Cheng, and Y. Liang, "Microstructure characteristic, mechanical properties and sintering mechanism of nanocrystalline copper obtained by SPS process," Materials Science and Engineering A, vol. 523, no. 1-2, pp. 134-138, 2009.

[23] T. B. Holland, I. A. Ovid'ko, H. Wang, and A. K. Mukherjee, "Elevated temperature deformation behavior of spark plasma sintered nanometric nickel with varied grain size distributions," Materials Science and Engineering A, vol. 528, no. 2, pp. 663-671, 2010.

[24] T. B. Holland, A. M. Thron, C. S. Bonifacio, A. K. Mukherjee, and K. Van Benthem, "Field assisted sintering of nickel nanoparticles during in situ transmission electron microscopy," Applied Physics Letters, vol. 96, no. 24, Article ID 243106, 2010.
[25] V. Y. Kodash, J. R. Groza, K. C. Cho, B. R. Klotz, and R. J. Dowding, "Field-assisted sintering of Ni nanopowders," Materials Science and Engineering A, vol. 385, no. 1-2, pp. 367371, 2004.

[26] G. Dirras, S. Bouvier, J. Gubicza, B. Hasni, and T. Szilágyi, "Mechanical characteristics under monotonic and cyclic simple shear of spark plasma sintered ultrafine-grained nickel," Materials Science and Engineering A, vol. 526, no. 1-2, pp. 201210, 2009.

[27] R. O. Wiedemann, U. Martin, H. J. Seifert, and A. Müller, "Densification behaviour of pure molybdenum powder by spark plasma sintering," International Journal of Refractory Metals and Hard Materials, vol. 28, no. 4, pp. 550-557, 2010.

[28] M. Kubota, "Properties of nano-structured pure Al produced by mechanical grinding and spark plasma sintering," Journal of Alloys and Compounds, vol. 434-435, pp. 294-297, 2007.

[29] M. Zadra, F. Casari, L. Girardini, and A. Molinari, "Spark plasma sintering of pure aluminium powder: mechanical properties and fracture analysis," Powder Metallurgy, vol. 50, no. 1, pp. 40-45, 2007.

[30] D. Fabrègue, J. Piallat, E. Maire, Y. Jorand, V. M. Jourdan, and G. Bonnefont, "Spark plasma sintering of pure iron nanopowders by simple route," Powder Metallurgy, vol. 55, no. 1, pp. 76-79, 2012.

[31] T. Skiba, P. Haušild, M. Karlík, K. Vanmeensel, and J. Vleugels, "Mechanical properties of spark plasma sintered FeAl intermetallics," Intermetallics, vol. 18, no. 7, pp. 1410$1414,2010$.

[32] K. Matsugi, N. Ishibashi, T. Hatayama, and O. Yanagisawa, "Microstructure of spark sintered titanium-aluminide compacts," Intermetallics, vol. 4, no. 6, pp. 457-467, 1996.

[33] H. Feng, Y. Zhou, D. Jia, and Q. Meng, "Rapid synthesis of Ti alloy with B addition by spark plasma sintering," Materials Science and Engineering A, vol. 390, no. 1-2, pp. 344-349, 2005.

[34] C. Shearwood, Y. Q. Fu, L. Yu, and K. A. Khor, "Spark plasma sintering of TiNi nano-powder," Scripta Materialia, vol. 52, no. 6, pp. 455-460, 2005.

[35] X. Lu, X. B. He, B. Zhang, L. Zhang, X. H. Qu, and Z. X. Guo, "Microstructure and mechanical properties of a spark plasma sinteredTi-45Al-8.5Nb-0.2W-0.2B-0.1Y alloy," Intermetallics, vol. 17, no. 10, pp. 840-846, 2009.

[36] A. Couret, G. Molénat, J. Galy, and M. Thomas, "Microstructures and mechanical properties of TiAl alloys consolidated by spark plasma sintering," Intermetallics, vol. 16, no. 9, pp. 11341141, 2008.

[37] X. S. Long, T. Jing, X. L. Juan, C. Y. Yong, Y. H. Bao, and H. J. Cai, "Microstructures and mechanical properties of TiAl alloy prepared by spark plasma sintering," Transactions of Nonferrous Metals Society of China, vol. 19, no. 6, pp. 14231427, 2009.

[38] L. L. Ye, Z. G. Liu, K. Raviprasad, M. X. Quan, M. Umemoto, and Z. Q. Hu, "Consolidation of MA amorphous NiTi powders by spark plasma sintering," Materials Science and Engineering A, vol. 241, no. 1-2, pp. 290-293, 1998.

[39] T. Murakami, A. Kitahara, Y. Koga, M. Kawahara, H. Inui, and M. Yamaguchi, "Microstructure of $\mathrm{Nb}-\mathrm{Al}$ powders consolidated by spark plasma sintering process," Materials Science and Engineering A, vol. 239-240, no. 1-2, pp. 672-679, 1997.

[40] T. Murakami, C. N. Xu, A. Kitahara et al., "Microstructure, mechanical properties and oxidation behavior of powder compacts of the Nb-Si-B system prepared by spark plasma sintering," Intermetallics, vol. 7, no. 9, pp. 1043-1048, 1999.

[41] C. K. Kim, H. S. Lee, S. Y. Shin, J. C. Lee, D. H. Kim, and S. Lee, "Microstructure and mechanical properties of $\mathrm{Cu}$-based bulk 
amorphous alloy billets fabricated by spark plasma sintering," Materials Science and Engineering A, vol. 406, no. 1-2, pp. 293299, 2005.

[42] X. Shi, H. Yang, and S. Wang, "Spark plasma sintering of $\mathrm{W}-15 \mathrm{Cu}$ alloy from ultrafine composite powder prepared by spray drying and calcining-continuous reduction technology," Materials Characterization, vol. 60, no. 2, pp. 133-137, 2009.

[43] C. Y. Xü, S. S. Jia, and Z. Y. Cao, "Synthesis of Al-Mn-Ce alloy by the spark plasma sintering," Materials Characterization, vol. 54, no. 4-5, pp. 394-398, 2005.

[44] T. T. Sasaki, T. Mukai, and K. Hono, "A high-strength bulk nanocrystalline Al-Fe alloy processed by mechanical alloying and spark plasma sintering," Scripta Materialia, vol. 57, no. 3, pp. 189-192, 2007.

[45] T. T. Sasaki, T. Ohkubo, and K. Hono, "Microstructure and mechanical properties of bulk nanocrystalline Al-Fe alloy processed by mechanical alloying and spark plasma sintering," Acta Materialia, vol. 57, no. 12, pp. 3529-3538, 2009.

[46] C. H. Bin, T. Kai, Y. Bin, and Z. J. Shan, "Nanostructured Al$\mathrm{Zn}-\mathrm{Mg}-\mathrm{Cu}$ alloy synthesized by cryomilling and spark plasma sintering," Transactions of Nonferrous Metals Society of China, vol. 19, no. 5, pp. 1110-1115, 2009.

[47] J. K. Rana, D. Sivaprahasam, K. S. Raju, and V. S. Sarma, "Microstructure and mechanical properties of nanocrystalline high strength Al-Mg-Si (AA6061) alloy by high energy ball milling and spark plasma sintering," Materials Science and Engineering A, vol. 527, no. 1-2, pp. 292-296, 2009.

[48] N. Saheb, "Spark plasma sintering of Al6061 and Al2124 alloys," Advanced Materials Research, vol. 284-286, pp. 16561660, 2011.

[49] A. Khalil, A. S. Hakeem, and N. Saheb, "Optimization of process parameters in spark plasma sintering Al6061 and Al2124 aluminum alloys," Advanced Materials Research, vol. 328-330, pp. 1517-1522, 2011.

[50] B. Akinrinlola, R. Gauvin, and M. Brochu, "Improving the mechanical reliability of cryomilled Al-Mg alloy using a twostage spark plasma sintering cycle," Scripta Materialia, vol. 66, no. 7, pp. 455-458, 2012.

[51] Y. Xiong, D. Liu, Y. Li et al., "Spark plasma sintering of cryomilled nanocrystalline $\mathrm{Al}$ alloy-part I: microstructure evolution," Metallurgical and Materials Transactions A, vol. 43, no. 1, pp. 327-339, 2012.

[52] S. Bathula, R. C. Anandani, A. Dhar, and A. K. Srivastava, "Synthesis and characterization of Al-alloy/SiCp nanocomposites employing high energy ball milling and spark plasma sintering," Advanced Materials Research, vol. 410, pp. 224-227, 2012.

[53] Z. Sadeghian, M. H. Enayati, B. Lotfi, and P. Beiss, "Development of $\mathrm{AL}-\mathrm{TiB}_{2}$ nanocomposite," in Proceedings of the Annual Meeting and Exhibition (TMS '11), vol. 2, pp. 129-136, March 2011.

[54] Z. Sadeghian, B. Lotfi, M. H. Enayati, and P. Beiss, "Microstructural and mechanical evaluation of $\mathrm{Al}^{-\mathrm{TiB}_{2}}$ nanostructured composite fabricated by mechanical alloying," Journal of Alloys and Compounds, vol. 509, no. 29, pp. 7758-7763, 2011.

[55] Z. Sadeghian, B. Lotfi, M. H. Enayati, and P. Beiss, "Fabrication of bulk $\mathrm{Al}-\mathrm{TiB}_{2}$ nanocomposite by spark plasma sintering of mechanically alloyed powder," in Technical Proceedings of the NSTI Nanotechnology Conference and Expo, NSTINanotech (Nanotech'10), pp. 107-110, June 2010.

[56] R. Vintila, A. Charest, R. A. L. Drew, and M. Brochu, "Synthesis and consolidation via spark plasma sintering of nanostructured Al-5356/ $\mathrm{B}_{4} \mathrm{C}$ composite," Materials Science and Engineering A, vol. 528, no. 13-14, pp. 4395-4407, 2011.
[57] B. Srinivasarao, C. Suryanarayana, K. Oh-ishi, and K. Hono, "Microstructure and mechanical properties of Al-Zr nanocomposite materials," Materials Science and Engineering A, vol. 518, no. 1-2, pp. 100-107, 2009.

[58] H. Kwon, M. Estili, K. Takagi, T. Miyazaki, and A. Kawasaki, "Combination of hot extrusion and spark plasma sintering for producing carbon nanotube reinforced aluminum matrix composites," Carbon, vol. 47, no. 3, pp. 570-577, 2009.

[59] J. Bhatt, N. Balachander, S. Shekher, R. Karthikeyan, D. R. Peshwe, and B. S. Murty, "Synthesis of nanostructured Al-Mg$\mathrm{SiO}_{2}$ metal matrix composites using high-energy ball milling and spark plasma sintering," Journal of Alloys and Compounds. In press.

[60] K. Dash, B. C. Ray, and D. Chaira, "Synthesis and characterization of copper-alumina metal matrix composite by conventional and spark plasma sintering," Journal of Alloys and Compounds, vol. 516, pp. 78-84, 2012.

[61] S. Libardi, M. Leoni, L. Facchini, M. D'Incau, P. Scardi, and A. Molinari, "Effect of the dispersion of nanometric silica particles on the thermal stability of a nanostructured iron based powder," Materials Science and Engineering A, vol. 445446, pp. 244-250, 2007.

[62] N. Saheb, A. Khalil, A. S. Hakeem, N. Al-Aqeeli, T. Laoui, and A. K. Qutub, "Spark plasma sintering of CNT reinforced Al6061 and Al2124 nanocomposites," submitted to. Journal of Composite Materials.

[63] A. M. Al-Qutub, A. Khalil, N. Saheb, and A. S. Hakeem, "Wear and friction behavior of Al6061 alloy reinforced with carbonnanotubes," submitted to. Wear.

[64] D. Nunes, V. Livramento, J. B. Correia et al., "Consolidation of Cu-nDiamond nanocomposites: hot extrusion vs spark plasma sintering," Materials Science Forum, vol. 636-637, pp. 682-687, 2010.

[65] B. K. Lim, C. B. Mo, D. H. Nam, and S. H. Hong, "Mechanical and electrical properties of carbon nanotube/Cu nanocomposites by molecular-level mixing and controlled oxidation process," Journal of Nanoscience and Nanotechnology, vol. 10, no. 1 , pp. 78-84, 2010.

[66] J. S. Kim, D. V. Dudina, J. C. Kim, Y. S. Kwon, J. J. Park, and C. K. Rhee, "Properties of Cu-based nanocomposites produced by mechanically-activated self-propagating high-temperature synthesis and spark-plasma sintering," Journal of Nanoscience and Nanotechnology, vol. 10, no. 1, pp. 252-257, 2010.

[67] D. H. Kwon, T. D. Nguyen, D. Dudina, J. S. Kim, Y. J. Yum, and Y. S. Kwon, "Properties of dispersion strengthened $\mathrm{Cu}-$ $\mathrm{TiB}_{2}$ nanocomposites prepared by spark plasma sintering," Diffusion and Defect Data B, vol. 119, pp. 63-66, 2007.

[68] D. H. Kwon, K. X. Huynh, T. D. Nguyen et al., "Mechanical behavior of $\mathrm{TiB}_{2}$ nanoparticles reinforced $\mathrm{Cu}$ matrix composites synthesized by in-situ processing," Materials Science Forum, vol. 510-511, pp. 346-349, 2006.

[69] D. H. Kwon, T. D. Nguyen, D. Dudina et al., "Thermal stability and properties of $\mathrm{Cu}-\mathrm{TiB}_{2}$ nanocomposites prepared by combustion synthesis and spark-plasma sintering," Materials Science Forum, vol. 534-536, no. 2, pp. 1517-1520, 2007.

[70] D. H. Kwon, D. N. Thuy, X. H. Khoa et al., "Mechanical, electrical and wear properties of $\mathrm{Cu}-\mathrm{TiB}_{2}$ nanocomposites fabricated by MA-SHS and SPS," Journal of Ceramic Processing Research, vol. 7, no. 3, pp. 275-279, 2006.

[71] K. Hanada, K. Yamamoto, T. Taguchi et al., "Further studies on copper nanocomposite with dispersed single-digitnanodiamond particles," Diamond and Related Materials, vol. 16, no. 12, pp. 2054-2057, 2007. 
[72] K. T. Kim, S. I. Cha, and S. H. Hong, "Microstructures and tensile behavior of carbon nanotube reinforced $\mathrm{Cu}$ matrix nanocomposites," Materials Science and Engineering A, vol. 430, no. 1-2, pp. 27-33, 2006.

[73] K. T. Kim, S. I. Cha, and S. H. Hong, "Hardness and wear resistance of carbon nanotube reinforced $\mathrm{Cu}$ matrix nanocomposites," Materials Science and Engineering A, vol. 448451, pp. 46-50, 2007.

[74] K. R. Ravi, A. Murugesan, V. Udhayabanu, R. Subramanian, and B. S. Murty, "Microstructure and mechanical property of $\mathrm{Fe}-\mathrm{Al}_{2} \mathrm{O}_{3}$ nanocomposites synthesized by reactive milling followed by spark plasma sintering," Materials Science Forum, vol. 710, pp. 291-296, 2012.

[75] J. G. Santanach, C. Estourns, A. Weibel, A. Peigney, G. Chevallier, and C. Laurent, "Mechanical and tribological properties of $\mathrm{Fe} / \mathrm{Cr}-\mathrm{FeAl}_{2} \mathrm{O}_{4}-\mathrm{Al}_{2} \mathrm{O}_{3}$ nano/micro hybrid composites prepared by spark plasma sintering," Scripta Materialia, vol. 64, no. 8, pp. 777-780, 2011.

[76] B. Li, Y. Li, M. Yue, and J. Zhang, "Preparation and properties of Nd2Fe14B/ $\alpha$-Fe nanocomposite permanent magnets," Chinese Journal of Materials Research, vol. 21, no. 3, pp. 319-323, 2007.

[77] A. Singh and S. P. Harimkar, "Spark plasma sintering of in situ and ex situ iron-based amorphous matrix composites," Journal of Alloys and Compounds, vol. 497, no. 1-2, pp. 121-126, 2010.

[78] V. Udhayabanu, K. R. Ravi, K. Murugan, D. Sivaprahasam, and B. S. Murty, "Development of $\mathrm{Ni}-\mathrm{Al}_{2} \mathrm{O}_{3}$ in-situ nanocomposite by reactive milling and spark plasma sintering," Metallurgical and Materials Transactions A, vol. 42, no. 7, pp. 2085-2093, 2011.

[79] S. Yamanaka, R. Gonda, A. Kawasaki et al., "Fabrication and thermal properties of carbon nanotube/nickel composite by spark plasma sintering method," Materials Transactions, vol. 48, no. 9, pp. 2506-2512, 2007.

[80] B. S. Kim, T. Sekino, T. Nakayama, M. Wada, J. S. Lee, and K. Niihara, "Pulse electric current sintering of alumina/nickel nanocomposites," Materials Research Innovations, vol. 7, no. 2, pp. 57-61, 2003.

[81] J. Umeda, K. Kondoh, and H. Imai, "Friction and wear behavior of sintered magnesium composite reinforced with CNT-Mg $\mathrm{Mg}_{2} \mathrm{Si} \mathrm{MgO}, "$ Materials Science and Engineering A, vol. 504, no. 1-2, pp. 157-162, 2009. 

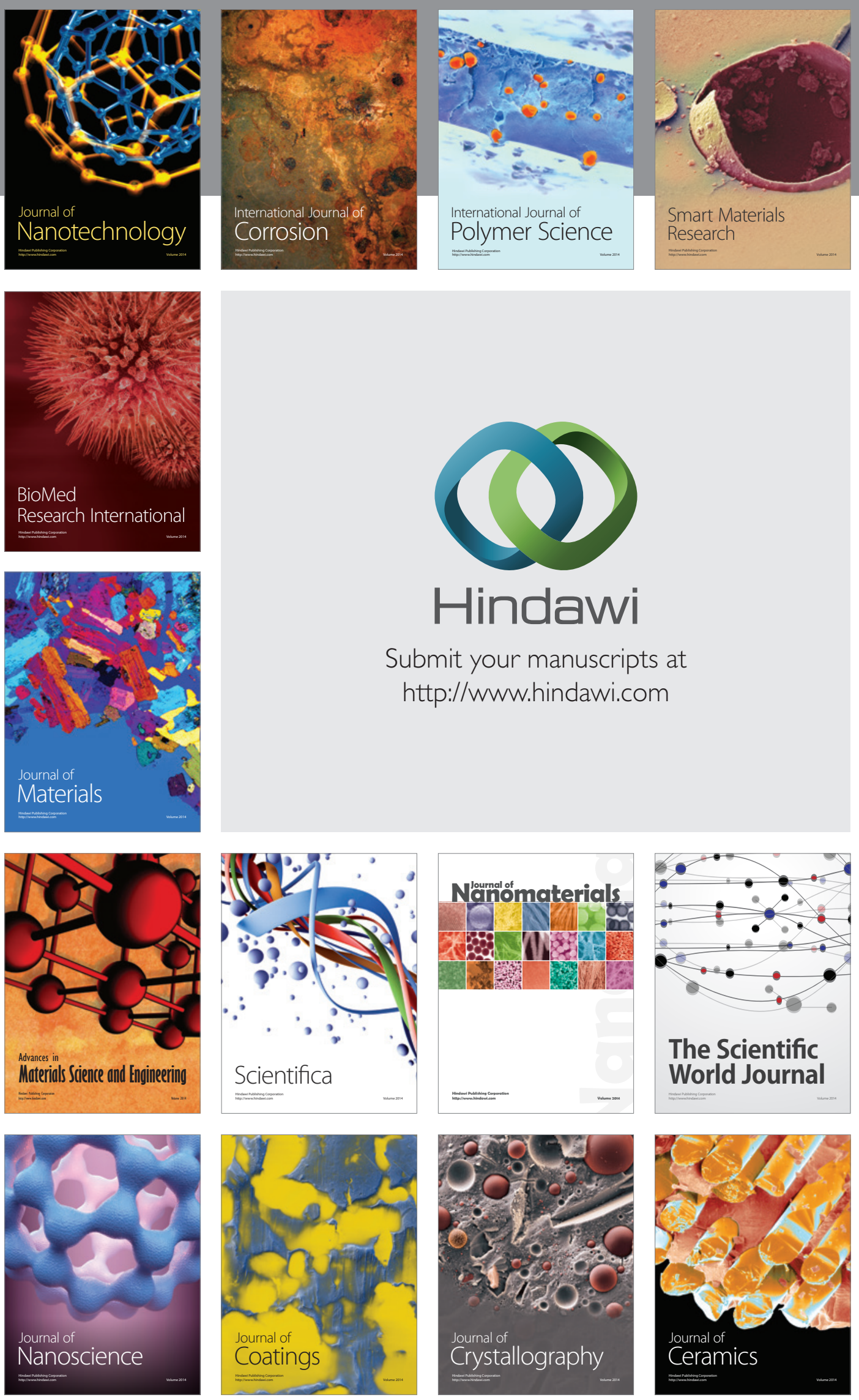

The Scientific World Journal

Submit your manuscripts at

http://www.hindawi.com

\section{World Journal}

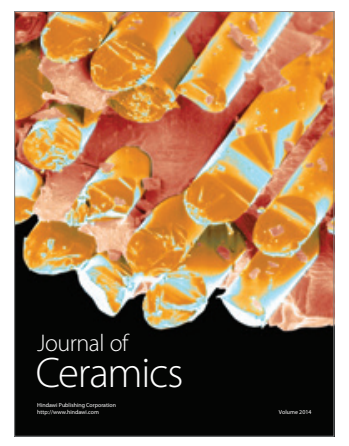

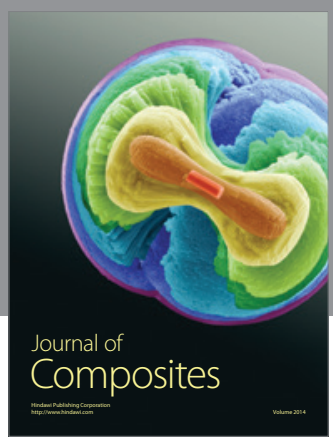
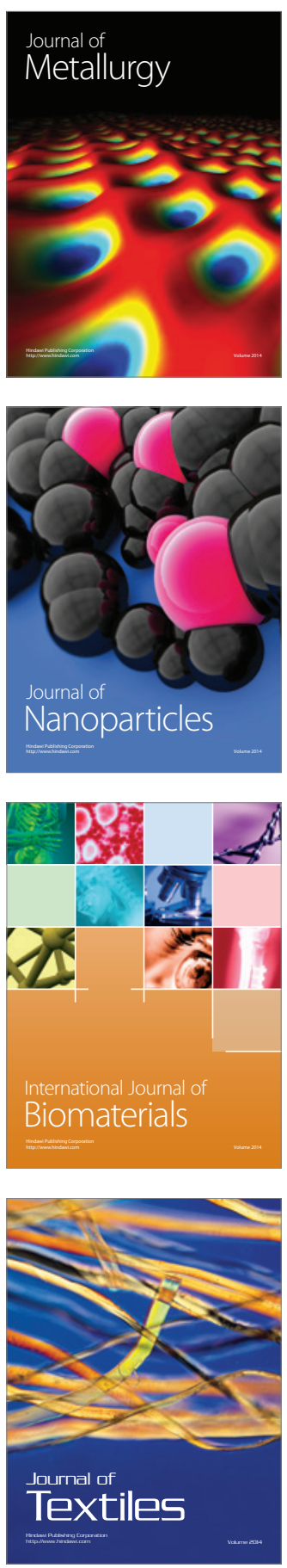